THURSDAY, JANUARY 26, I 888.

\section{ODIUM MEDICUM.}

$\mathrm{N}^{\mathrm{O}}$ one will deny the truth of the saying, "All men are mortal," but very few have any definite feeling that it applies to them personally so long as they are in the possession of health and'strength. Almost everyone, however, has either suffered at a former time, is suffering now, or is afraid of suffering at some future time, from ailments of some sort; and therefore the treatment of disease has a personal interest for everyone. On this account the discussions which have been going on for about a month in the Times regarding homœopathy have attracted a good deal of attention; but it is difficult for lay readers to understand the merits of the discussion thoroughly unless they know something about the "pathies" generally. The fundamental idea of the "pathies" is that the body does not readily tolerate more than one diseased process at the same time, and therefore one morbid condition may be driven out by inducing another.

The nucleus of our present medicine may be said to consist of the accumulated experience in the observation and treatment of disease possessed by the priests of Cos, and recorded by Hippocrates, who is justly regarded as the father of medicine. His treatment was based upon empiricism, and was not governed by any absolute rule, for, although he stated that in general diseases are cured by their contraries, he also allowed that disease might sometimes be relieved by medicines which produced similar symptoms, and mentioned that under certain circumstances purgatives will bind the bowels, astringents will loosen them, and substances which cause cough and strangury will also cure them.

The principle that contraries are cured by contraries, e.g. that constipation is cured by purgatives, attained so much importance under Galen and his followers, that the other principle of like being cured by like was nearly lost sight of, and so the antipathic school had for a long time the preponderance. But the use of evacuants, which formed a large portion of the practice of Hippocrates and of medical practice down to the present day, could not always be brought under the head of antipathy, and so it came to be admitted that one abnormal condition in the body might be relieved by inducing another, which was neither of the same kind as itself, nor of an opposite kind, but was simply of a different nature, and this is the allopathic form of treatment. As an example of this we may take the fact that a pain in the head may be cured by a medicine which does not act on the head at all, but upon the bowels.

The antipathic and the allopathic systems of medicine were in vogue in the time of Hahnemann, and their imperfections were very evident to a man of his mental power and acuteness. He saw clearly that the enormous doses which were given in his time were often productive of great harm, and in experimenting with smaller doses he found that his results were better. $\mathrm{He}$ also found, what had been noted before by Hippocrates, that he obtained curative effects from small doses of remedies which in large doses produced symptoms similar to those of the disease. In the recognition of this fact Hahnemann agreed with Hippocrates; but, while the father of medicine, testing everything by experiment and relying simply on the result of experience, regarded the rule "similia similibus curantur" as only of partial application, Hahnemann converted it into a universal rule. $\mathrm{He}$ began at first by relying on experiment, and spoke of pure experience as the "only infallible oracle of medicine," but he afterwards quitted this sure ground, and committed himself unreservedly to a belief in his theoretical opinions, whether supported by facts or not, and said in regard to his doses that the maxim as to the very smallest being the best is " not to be refuted by any experience in the world.' The essence of his system of homœopathy consisted in the universal application of the rule regarding the similar action of the drug to that of the disease, and in the smallness of the dose.

Some modern homœopathists are inclined to regard the minute dose as not essential to homœopathy, but Hahnemann says: "The appropriation of the medicine to any given case of disease does not depend solely upon the circumstance of its being perfectly homœopathic, but also upon the minute quantity of the dose in which it is administered." The extent to which he carried the dilution of his medicines was extraordinary, and he imagined that the more they were diluted the more potent did they become. Thus he says in his "Materia Medica Pura" (Dr. Dudgeon's translation) that the curative power of aconite is marvellous when it is given "in the dose of a thousandth part of a drop of the decillionth development of power." But even this astoundingly minute dose was unnecessarily strong in some cases, in which he thought "a single momentary olfaction at a phial containing a globule the size of a mustard-seed, moistened with the decillionth potency of aconite, is quite sufficient." But it is difficult for those who have not studied the action of potent drugs like aconite to form any definite judgment regarding their effect in large and small doses; so that it may be worth while to give his views regarding vegetable charcoal, a substance about which everyone can form an opinion. Most people will be surprised to hear that Hahnemann gives no fewer than 720 symptoms as being caused by a few grains of vegetable charcoal diluted a million-fold with milk sugar. These symptoms are of the most varying nature, from aching of the corns to headache, palpitation, and rheumatism, with sometimes a peevish temper, and at other times an excessively cheerful one. The variety and severity of these symptoms clearly show that they were not due to the vegetable charcoal at all, but would have occurred whether the charcoal had been taken or not. But the most remarkable instance of a fallacy in Hahnemann's conclusions appears in his famous experiment on the action of cinchona bark in producing ague, which has been regarded by homøoopathists as one of the most important proofs of the truth of the system. Hahnemann, at one time of his life, had suffered from ague, as we learn from Ameke's "History of Homœopathy," but he had probably been free from it for some time before he made his experiment with cinchona. It is well known that persons who have once suffered from ague are apt to have it return when their digestion is disturbed, or when they are subject to depressing influences. The dose of powdered cinchona bark which Hahnemann took was 
very large, and similar doses have produced in other people vomiting and gastro-intestinal irritation. In Hahnemann it produced symptoms of ague, but instead of concluding that the cinchona had simply brought back an attack of his old enemy, by acting as an irritant to his stomach, he concluded that cinchona bark had a specific power to produce ague. Others who have tried the experiment, and who have not had ague before, have naturally failed.

Hahnemann's system was greatly ridiculed and opposed both during his life and since, and yet, in spite of its absurdities in regard to dose, it has a number of adherents. The reasons of this are perhaps not very hard to find. For instead of homocopathic medicines being disagreeable to the patient, as those of regular practitioners too often are, they are given in a form which is rather pleasant than otherwise, and Hahnemann's rules of diet and regimen were very different from those followed by regular practitioners of his time. While they were apt to consider that anything that seemed agreeable to the patient was dangerous and to be forbidden, Hahnemann, placing full reliance on the influence of his infinitesimal doses, allowed the clesire of the patient for food and drink to be gratified within proper limits, and the temperature of the chamber as well as the quantity of the bed-clothes to be regulated according to the wishes of the patient. There can be no doubt that the attention given by Hahnemann and his followers to diet and regimen have been of great service, not only to the patients they have treated, but to the whole medical profession. It is obvious that such a system as Hahnemann's-gratifying the desires of the patient so far as it was judicious, giving remedies in such minute doses as could at all events do no harm, and at the same time encouraging the patient with the positive assurance that the infinitesimal doses were of the utmost potency to effect a cure-had a great advantage over the system of allopathy. This advantage was to a certain extent shared by antipathy, inas much as both it and homœopathy acted on a definite plan, and chose their drugs according to what they supposed to be fixed laws.

Although so far behind the other two in some respects, allopathy had this great advantage over them, that it depended simply on the results of experiment; and although it might be influenced, and was influenced at times, by prevailing fashions, its followers were still searching after truth, while the others falsely supposed they had already found it. With the development of pathology and a truer insight into the nature of disease, the term allopathy has fallen to a great extent into disuse, and most of what we might term the orthodox practitioners of the present day object to range themselves under any "pathy" whatever, but aim at a rational practice founded on the one hand upon the knowledge of the nature of disease, and on the other of the action of remedies. Where these are insufficient to guicie them, they fall back simply upon empiricism; expecting, however, that before long, wider knowledge may increase their power to cure their patients. Their power is no doubt very greatly on the increase; and we have only to look at the fact that within the last few years they have been able by the use of substances belonging to the aromatic series of chemical compounds to regulate the temperature of their patients, so that whereas formerly physicians were obliged to stand by idly while their patients died of high fever, they can now prevent the temperature from rising too high with almost perfect certainty, and thus save their patients' lives. Every day fresh contributions are being made both to the physician's knowledge of the nature of disease and his power to modify it or prevent it.

Yet still the regular physician is but a seeker after truth, and as yet no infallible rule by which to select his medicines is known to him. He cannot lay down with dogmatism that the medicine which he is about to administer is the only one or the very best one that can possibly be given, as a homœopath might do. $\mathrm{He}$ is therefore to a certain extent at a disadvantage as compared with the homœopath, especially in the treatment of those cases where the disease is not extremely severe, and where the effect upon the mind of the patient counts for as much or more than the action of the medicine itself. The want of a definite rule on the one hand affords an opportunity for the homœopath to sneer at the regular practitioner, while at the same time he complains that the regular practitioner refuses to have any dealings with him. But there seems to be no other course open to the regular practitioner, for he considers that the homœeopath must do one of two things : he either believes in homœopathy, or he does not. If he believes in homocopathy as founded by Hahnemann, and prescribes for his patients infinitesimal doses with a conviction that he is actually modifying the disease from which they suffer, the regular practitioner regards him as a fool; while he would apply a still stronger term to the man who does not believe in Hahnemann's system, and uses powerful drugs in large doses, but nevertheless professes to treat his patients homœopathically. It is as useless for a regular practitioner to treat a patient along with a believer in homœopathy as it is for a modern chemist to undertake a joint research with a believer in phlogiston ; and therefore the regular practitioner refuses to meet him in consultation so long as he holds homœopathic doctrines. But if the homoeopath gives up his belief in infinitesimal doses, and in the universal application of the rule "similia similibus curantur," he has given up the essentials of homoopathy, and has no more title to the name of homoeopath than Hippocrates had. If he has given up the thing he should give up the name and join the ranks of orthodoxy, but if he still retains the name for the sake of gain he can hardly expect to be welcomed by the orthodox part of the medical profession. It is very unfortunate that the "odium medicum" should exist, but the homœopaths seem more to blame for it than the followers of rational medicine.

\section{DARWINISM AND ETHICS.}

The Ethical Import of Darvinism. By Jacob Gould Schurman, M.A., D.Sc., Sage Professor of Philosophy in Cornell University. (London: Williams and Norgate, I888.)

Morality and Utility. By George Payne Best, B.A., M.B. (London: Trübner and Co., I 887.)

WE will consider these two little books together, as in some measure the latter, although earlier in publication, answers the former. 